\title{
Dissemination and Implementation Science in Primary Care Research and Practice: Contributions and Opportunities
}

\author{
Jodi Summers Holtrop, PhD, MCHES, Borsika A. Rabin, MPH, PhD, PharmD, and
} Russell E. Glasgow, PhD

Dissemination and Implementation Science (DIS) is a growing research field that seeks to inform how evidence-based interventions can be successfully adopted, implemented, and maintained in health care delivery and community settings. In this article, an overview of DIS and how it has contributed to primary care delivery improvement, future opportunities for its use, and DIS resources for learning are described. Case examples are provided to illustrate how DIS can be used to solve the complex implementation and dissemination problems that emerge in primary care. Finally, recommendations are made to guide the use of DIS to inform and drive improvements in primary care delivery. ( $\mathrm{J}$ Am Board Fam Med 2018;31:466-478.)

Keywords: Delivery of Health Care, Health Resources, Implementation Science, Primary Health Care

Research in primary care has highlighted many new developments in the past decade including training programs, scope of care, care teams, treatments, and payment models. ${ }^{1,2}$ These changes have resulted in advances, opportunities, and challenges. Some of the most recent and ongoing developments in primary care include a focus on patientcentered care, the concept and implementation of the patient-centered medical home ${ }^{3,4}$, the use of electronic medical records and meaningful use standards ${ }^{5,6}$, payment redesign such as the Medicare Access and CHIP Reauthorization Act of $2015^{7}$ and Merit-based Incentive Payment System $^{8}$, Maintenance of Certification requirements ${ }^{9,10}$ as well as practice transformation strategies to implement these initiatives. Complicating

This article was externally peer reviewed.

Submitted 3 July 2017; revised 3 February 2018; accepted 6 February 2018.

From the Department of Family Medicine, University of Colorado Denver School of Medicine, Aurora, CO (JSH, BAR, REG); University of California San Diego School of Medicine, La Jolla, CA (BAR).

Funding: none.

Conflict of interest: none declared.

Corresponding author: Jodi Summers Holtrop, $\mathrm{PhD}$ MCHES, University of Colorado Denver School of Medicine, Department of Family Medicine, 12631 E. 17th Avenue, Aurora CO, 80045 (E-mail: Jodi.holtrop@ucdenver.edu). matters further are new developments in the patient population including aging and the associated increasing burden of chronic illness, health equity and social determinants of health issues, and the coming era of precision medicine. ${ }^{11-13}$

Primary care practitioners and researchers are in the forefront of making these changes happen. Achieving the goals of these initiatives, however, can be challenging for a multitude of reasons. It is well known that most innovations and evidencebased practices do not make it into practice or, if they do, take an average of 17 years. ${ }^{14}$ Some of the reasons for this delay or failure in implementation of new initiatives are contextual and include lack of training and policy support, reimbursement issues, and lack of appropriate dissemination infrastructure. The complicated demands being placed on increasingly complex systems require that a new strategy and science be in place to be successful at the dissemination, implementation, and sustainability of evidence-based programs. Dissemination and implementation science (DIS), a relatively new area of health research, shows increasing promise to address many of these issues and bridge the gap between new, efficacious or evidence-based practices, guidelines, policies and interventions, and routine practice. DIS studies how interventions can 
be designed to work in real-world clinical and community settings, and identifies and evaluates the strategies that produce these results. ${ }^{15,16}$ The focus is on designing interventions and identifying implementation strategies that work in real life and across diverse (and especially low resource), complex settings and populations.

Although others have provided an introduction of DIS for health services researchers and practicebased research networks ${ }^{17-19}$, the purpose of this article is to describe DIS - what it is, what methods it uses-within a focus on how it can contribute to primary care medical practice, for both researchers and practitioners. We summarize pertinent DIS frameworks, show how DIS approaches are different from conventional research, illustrate their use with an example planning and evaluation aid, provide 2 use cases, and conclude with resources for DIS strategies in primary care.

\section{Dissemination and Implementation Science-What It Is and What It Can Do for Primary Care}

To address the complex, multi-level issues above, we usually attempt to use strategies that have worked in the past and approaches we have been taught. We try to just work harder or come up with a better or more comprehensive intervention. The problem is that in our challenging and rapidly changing context these methods often do not work to address our most pertinent implementation challenges. ${ }^{20,21}$ Different questions need to be asked, and different solutions and methods applied. DIS can help to address these problems. To achieve population impact, we need to understand how well an intervention (we will use the term intervention to refer to both programs and policies) achieves it intended effects, what implementation strategies are effective, how broadly and how well that intervention is implemented to achieve those effects, if there are unintended consequences, and what the cost, generalizability, and sustainability potential are for the intervention. Although research has placed much emphasis on the former (ie, intervention effectiveness), it has paid little attention to the latter issues that fall under the umbrella of DIS.

\section{What Exactly Is DIS and How Is It Alike and Different from Other Evaluations or Research?}

The most frequently used definitions of dissemination and implementation science indicate that dissemination research is "the systematic study of processes and factors that lead to widespread use of an evidence-based intervention by the target population" and suggests that implementation research "seeks to understand the processes and factors that are associated with successful integration of evidence-based interventions within a particular setting." ${ }^{22,23}$ Therefore, DIS seeks to bridge the gap between evidence-based interventions and their uptake in community clinical practice.

It seems important to point out how DIS is similar and different from both quality improvement and traditional efficacy research. Although both DIS and quality improvement (QI) address real-world practice problems, the ultimate goal and related methodologies are different. ${ }^{24}$ DIS varies from QI in that it produces generalizable knowledge (not only finding solutions to a problem in a specific local setting) and seeks to apply principles of hypothesis testing and methodological rigor. In contrast, QI approaches seek to ask and answer questions that are focused predominantly on determining what works in a particular local setting and engaging participants in the process of improvement. ${ }^{25,26}$ DIS studies typically use mixed methods, including both qualitative and quantitative methods, and focus on identifying factors that affect uptake on multiple levels, including patient, provider, clinic, facility, organization, and many times, the broader community and policy environment. DIS also requires a solid grounding in theory and usually the involvement of transdisciplinary research teams. ${ }^{17}$ In recent years, DIS has increasingly looked at ways in which designs and strategies used in QI could be used for DIS; the synthesis of these 2 approaches is sometimes called "improvement science." 27

What is often more confusing is the place of DIS in the continuum of types of research. Many distinguish DIS from what is traditionally thought of as efficacy research-identifying a novel approach and testing it in a randomized controlled trial under tightly controlled conditions. In contrast, DIS is inherently pragmatic and seeks to ask real-world implementation questions including use under more typical or diverse conditions. Table 1 summarizes key dimensions distinguishing DIS from efficacy research. It is important to note that both are needed. Efficacy research seeks to maximize internal validity and answer whether a new intervention is truly having the intended effect. DIS 
Table 1. Frequent Issues in Primary Care Research, with Efficacy and Dissemination and Implementation Science (DIS) Approaches to These Issues

\begin{tabular}{|c|c|c|}
\hline Content Issue & Efficacy Approach & $\begin{array}{c}\text { DIS Approach and Framework } \\
\text { Considerations }\end{array}$ \\
\hline $\begin{array}{l}\text { Multi-level context of problems and } \\
\text { programs }\end{array}$ & $\begin{array}{l}\text { One-level model. Focus is } 1: 1 \text {, } \\
\text { patient-provider, or family } \\
\text { to health care team only }\end{array}$ & $\begin{array}{l}\text { Multi-level model including individual, } \\
\text { organizational and health system } \\
\text { levels. Consider CFIR or PRISM } \\
\text { and mixed methods context } \\
\text { assessments }\end{array}$ \\
\hline $\begin{array}{l}\text { Representativeness (at multiple levels) } \\
\text { and Reach }\end{array}$ & $\begin{array}{l}\text { Often not addressed or } \\
\text { considered to be not } \\
\text { possible to assess or } \\
\text { influence }\end{array}$ & $\begin{array}{l}\text { RE-AIM framework focus on adoption, } \\
\text { settings, and representativeness }\end{array}$ \\
\hline $\begin{array}{l}\text { Program selection, innovation design, } \\
\text { and feasibility }\end{array}$ & $\begin{array}{l}\text { Select maximally effective or } \\
\text { most comprehensive } \\
\text { program regardless of other } \\
\text { factors }\end{array}$ & $\begin{array}{l}\text { Emphasis on feasibility, costs, } \\
\text { minimum intervention needed for } \\
\text { change (MINC) })^{73}\end{array}$ \\
\hline $\begin{array}{l}\text { Variability and adaptation-across } \\
\text { sites and over time }\end{array}$ & $\begin{array}{l}\text { Considered bad; poor fidelity } \\
\text { likely means poor results; } \\
\text { hard to standardize }\end{array}$ & $\begin{array}{l}\text { Inevitable, need to study and guide } \\
\text { appropriate adaptation to context }\end{array}$ \\
\hline $\begin{array}{l}\text { Sustainability and dissemination of } \\
\text { program or innovation }\end{array}$ & $\begin{array}{l}\text { Think about this only at } \\
\text { conclusion of evaluation }\end{array}$ & $\begin{array}{l}\text { "Design for Dissemination" from } \\
\text { outset of the study }\end{array}$ \\
\hline
\end{tabular}

CFIR, consolidated framework for implementation research; MINC, minimum intervention needed for change; PRISM, practical, robust implementation science model; RE-AIM, reach, effectiveness, adoption, implementation, maintenance.

research addresses issues that make it possible to implement an empirically supported program or policy (often referred to as an evidence-based intervention) into actual care delivery and determine the conditions under which it is more and less effective. For example, for the issue of representativeness, an efficacy study would seek to have a narrow, clearly defined population and would be conducted in optimal settings to minimize variability and confounding factors to more cleanly understand the intervention's effect on a targeted population. In contrast, a DIS study would include a broad sample of patients, staff, and practices to understand how different populations respond to the intervention. The interventions would be delivered by staff typical of those settings rather than experts in academic centers.

\section{Using PRECIS-2 to Determine the Explanatory to Pragmatic Continuum}

To determine the degree to which a study or project is pragmatic or more of a efficacy (ie, explanatory) research study, we recommend using the Pragmatic-Explanatory Continuum Indicator Summary (PRECIS-2) "wheel" to show where a particular study lies on the continuum of explanatory to pragmatic research. ${ }^{28}$ This aid has been used to both plan and report findings of research studies; it summarizes at a glance how pragmatic a study is and has been used by the National Institutes of Health (NIH) and Patient-Centered Outcomes Research Institute characterize pragmatic studies. ${ }^{29-31}$ No study is completely pragmatic or completely explanatory, but use of the PRECIS-2 approach can help to clarify where one's study lies on each of the 9 dimensions relative to the study goal.

Another key feature of DIS is that it also studies the strategy for implementation of the intervention and not just an intervention. For example, a researcher may wish to study the uptake of adding a new process for chronic pain management using patient-clinician agreements or practice facilitation. The intervention is the chronic pain agreement and protocol for reducing opioid use. However, DIS also studies the extent that the intervention gets used in typical settings and what implementation strategies are most cost-effective to make the intervention successful. Implementation strategies might include consensus building meetings among key staff to determine work flows and referral patterns, training for clinicians and staff on how to use and document the results in the agreement, audit and feedback on initial success, and adaptations based on this feedback. The value of looking at the implementation process is that it allows us to understand what needs to be done to get an effective intervention used routinely. 


\section{Adaptation Versus Fidelity}

A key issue in implementation research is the concept of fidelity versus adaptation. The traditional efficacy view is that the intervention protocol needs to be consistently delivered without variation (ie, fidelity). Delivering the protocol as developed by the research team is considered necessary for determining causality. However, once an intervention is taken up in practice, there is always variation in how it is used across settings, staff, patients, or time. This leads one to ask, what components are core and need to be delivered consistently, and which need to be adapted or tailored to different populations, settings, and conditions? Does it matter how and who implements them and using what mechanism? These questions are in the domain of adaptation. In fact, effective implementers know that adaptation can result in improved outcomes if the adaptations retain the core elements important to the outcome desired, but also create a better "fit" to the setting. ${ }^{21,32}$

A critical difference between more traditional efficacy research and DIS is in the question each tries to answer. Although efficacy trials answer the question: "does this intervention work under tightly controlled conditions?" DIS ask a more complex question of "how, when, with whom, where, and under what circumstances does this intervention work?" The use of mixed methods is often necessary to comprehensively study implementation. Although one could study an implementation process using only quantitative measures such as clinical data and numerically scored survey responses, this would miss important understanding that could be gleaned from qualitative methods such as interviews or observations. Extended discussion on qualitative methods for DIS can be found elsewhere. ${ }^{33-35}$

\section{DIS Models for Primary Care Practice and Research}

How might primary care team members use a DIS perspective in improving the quality, impact, and efficiency of their work? How might a primary care researcher use DIS approaches to study what makes an intervention implement well, be generalizable, and be sustainable? In this section, we provide some answers to these questions.

The use of DIS models can provide a useful starting point for this journey. There are a plethora of DIS models available for planning and evaluation of DIS activities. A number of reviews and an interactive web-based tool (Dissemination and Implementation Models in Health: http://dissemination-implementation.org) are available to guide decisions on how to select, combine, and adapt them. ${ }^{36-38}$ Although some DIS models might seem too complicated to implement in primary care practice, others are more practical, intuitive, and transparent and can be quite helpful in organizing the context and activities of complex primary care settings and processes.

In this article, we use the reach, effectiveness, adoption, implementation, maintenance (RE-AIM) framework (reach, effectiveness, adoption, implementation, and maintenance; www.reaim.org) to provide further guidance for DIS. We chose this framework as it has been broadly used across topics and settings and has been successfully operationalized by researchers and practitioners alike. RE-AIM is a planning and evaluation model for consideration of key dimensions to plan for and assess how well an intervention might work in practice. ${ }^{39}$ RE-AIM includes 5 dimensions to call attention to the importance of measuring not only a traditional clinical outcome (ie, effectiveness), but also other implementation outcomes that are less frequently assessed but critical to producing broad impact. RE-AIM has been used widely. ${ }^{40,41}$

\section{DIS for Primary Care Practitioners}

In Table 2, we illustrate how questions associated with RE-AIM may be used to identify key questions for planning an effective quality improvement project or help with population health management. For practitioners, planning and evaluation is more the framework for consideration, rather than formal research. Considerations include the contextual variables that are likely to impact the implementation process, such as costs, "fit," and burden to deliver and continue the intervention, such as on workflows and unanticipated consequences. Increasingly important is the extent to which team members can develop a common mindset and goals and use quality improvement processes to work toward a desired outcome.

Practitioners may have had difficulty trying to apply a DIS or other conceptual model to their practice setting and questions. RE-AIM and other pragmatic models have been used successfully for planning and evaluation by clinicians and community leaders. A recent article provides explicit guidance for pragmatic use of RE-AIM when one does not have the resources or scientific expertise available in a well-funded grant. ${ }^{42}$ 
Table 2. Planning Questions for Primary Care Interventions Intended to Produce Clinical Impact Using the RE-AIM Framework

RE-AIM Element and

Definition*

Core Questions

Supplemental and Probe Questions

Reach: The absolute number, proportion, and representativeness of individuals who are willing to participate in a given initiative

Effectiveness: The impact of an intervention on important outcomes, including potential negative effects, quality of life, and economic outcomes.

Adoption: The absolute number, proportion, and representativeness of settings and intervention agents who are willing to initiate a program.

Implementation: At the setting level, implementation refers to the intervention agents' fidelity to the various elements of an intervention's protocol. This includes consistency of delivery as intended and the time and cost of the intervention.
Who will benefit from the initiative?

Individuals (e.g., students, employees, patients, kids, parents, community members)

Whom do you plan to reach in your initiative? Can you define the target population(s)?

How or where will you reach them?

How will you advertise and promote the program? Who needs to approve these methods?

How will you know if you reached them and Will you reach those at higher risk or with who participated? fewer resources? How will you know?

What are the most important outcomes you expect to see?

Individuals (e.g., more physical activity, better quality of life, less bullying, less absenteeism, less drug use)

How likely is it that your initiative will achieve its key outcomes?

How will you know if the outcomes were achieved?

What are the biggest threats to seeing the outcomes you want?

What measures will be used?

Who will care about the outcomes?

What unintended consequences or outcomes might there be (positive or negative)?

What has gone wrong in other similar initiatives? What has gone well that wasn't anticipated?

In what settings do you want to participate?

Settings or organizations (e.g., uptake in worksites, schools, clinics, health departments, community organizations)

What kinds of setting or organizations will need to participate in the program or policy initiative?

Who will care about this?

How will the intended audience hear about this? Why will they want to participate? What is needed to encourage them to get engaged?

Who will deliver the program or policy (actually do the work) and do they have the skills and time?

Who is willing to help?

What skill sets are needed?

Why might staff and volunteers want to participate?

How many of these settings and organizations do you estimate will use the program or participate in your policy?

How will you know if organizations used the initiative?

What supports (for example, policies or similar programs) or threats are there?

Who can help gather information about this?

What is needed to train volunteers and who will do this?

How will the initiative be delivered, including adjustments and adaptations?

Settings or organizations (e.g., schools, workplaces, clinics, community settings or organizations)

To what extent will the key aspects of the program or policy be delivered as intended?

What adaptations or modifications do you think are necessary to help implement the initiative in your chosen settings?

How will you know what adaptations or modifications were made during the program?

What are some of the possible obstacles to implementation?
What are the key elements of the initiative that must be delivered to be successful? Which ones are less important for success?

What are likely implementation challenges you will need to overcome? How might you adapt to address these?

Who can help you keep track of modifications or adjustments made?

Are there competing projects or programs to consider? 


\begin{tabular}{|c|c|c|}
\hline $\begin{array}{l}\text { RE-AIM Element and } \\
\text { Definition* }\end{array}$ & Core Questions & Supplemental and Probe Questions \\
\hline & $\begin{array}{l}\text { What costs (including time and burden, } \\
\text { not just money) need to be considered? }\end{array}$ & $\begin{array}{l}\text { Are these costs and resources available } \\
\text { and reasonable to ask for (high } \\
\text { enough priority?) }\end{array}$ \\
\hline $\begin{array}{l}\text { How will you keep track of } \\
\text { implementation? }\end{array}$ & Who will do this and is this feasible? & \\
\hline \multirow{7}{*}{$\begin{array}{l}\text { Maintenance: The extent to } \\
\text { which a program or policy } \\
\text { becomes institutionalized or } \\
\text { part of the routine } \\
\text { organizational practices and } \\
\text { policies. Maintenance in the } \\
\text { RE-AIM framework also has } \\
\text { referents at the individual } \\
\text { level. At the individual level, } \\
\text { maintenance has been defined } \\
\text { as the long-term effects of a } \\
\text { program on outcomes after } 6 \\
\text { or more months after the most } \\
\text { recent intervention contact. }\end{array}$} & \multicolumn{2}{|c|}{ What will happen over the long term? [including dissemination] } \\
\hline & \multicolumn{2}{|c|}{$\begin{array}{l}\text { Individuals and Settings (e.g., sustained infrastructure; longer term benefits to children, } \\
\text { employees, patients, students,) }\end{array}$} \\
\hline & $\begin{array}{l}\text { Can organizations sustain the initiative } \\
\text { over time and are there plans to leave } \\
\text { trained staff in place? }\end{array}$ & $\begin{array}{l}\text { What infrastructure will be needed to } \\
\text { sustain the initiative? Is there an } \\
\text { infrastructure and funding that will } \\
\text { remain? }\end{array}$ \\
\hline & $\begin{array}{l}\text { How likely is your initiative to produce } \\
\text { lasting effects for individual } \\
\text { participants? }\end{array}$ & $\begin{array}{l}\text { How will individuals be delivered key } \\
\text { program components over time? Will } \\
\text { they stay in contact? }\end{array}$ \\
\hline & $\begin{array}{l}\text { How will you be able to follow your } \\
\text { initiative for an extended period of } \\
\text { time? }\end{array}$ & $\begin{array}{l}\text { How will you continue to track its } \\
\text { success and provide ongoing } \\
\text { feedback? "How's it working for } \\
\text { you?" }\end{array}$ \\
\hline & $\begin{array}{l}\text { How will you get the word out about } \\
\text { your product and lessons learned? }\end{array}$ & $\begin{array}{l}\text { What easy to understand materials can } \\
\text { you produce to tell others about your } \\
\text { lessons learned? How will you know } \\
\text { that they are effective and reaching } \\
\text { your audience? }\end{array}$ \\
\hline & $\begin{array}{l}\text { What are likely modifications or } \\
\text { adaptations that will need to be made } \\
\text { to sustain the initiative over time (e.g. } \\
\text { lower cost, different staff, reduced } \\
\text { intensity, different settings)? }\end{array}$ & $\begin{array}{l}\text { How can you track the major changes } \\
\text { made over time? }\end{array}$ \\
\hline
\end{tabular}

*RE-AIM.org.

Table adapted from the UPSTREAM evaluation program funded by the Colorado Health Foundation and the Evaluation Hub of the University of Colorado Department of Family Medicine; Also adapted from "RE-AIM: Rate Your Plan Exercise" and the "RE-AIM: Extended Consort Diagram"; and elements from PRISM.

\section{DIS for Primary Care Researchers}

For researchers, RE-AIM is a predominant model and has proven successful for measuring the key aspects of a DIS study. A newer model that builds on RE-AIM is the Practical, Robust, Implementation and Sustainability Model (PRISM). ${ }^{43}$ PRISM includes the RE-AIM outcome elements, but expands beyond them to include consideration of contextual factors at the levels of the intervention, individual, and system, and how those factors affect the RE-AIM dimensions. These additional contextual issues, especially aspects such as the implementation and sustainability infrastructure, provide important clues to factors that may impact the extent to which RE-AIM outcomes and population results are achieved. ${ }^{44}$

Another useful guide for researchers in planning and tracking the data from a DIS study is to use the Expanded CONSORT Figure. ${ }^{45}$ Many researchers use, and most medical journals require, the CONSORT diagram ${ }^{46}$ to map out the subjects who participate, continue, and are analyzed in an intervention. The expanded CONSORT diagram includes adoption issues that occur before individual-level recruitment (eg, setting and staff level inclusion, exclusion, participation, and representativeness), as well as maintenance or sustainability after a study is completed..$^{3,47,48}$ These additions to the standard CONSORT diagram help to enhance transparency of research and to address external validity and public health impact.

\section{Case Studies: Using a DIS Approach Example No. 1: Integration of Brief, Validated Measures of Health Behaviors, Mental Health, and Patient Preferences into Electronic Medical Records (MOHR Study)}

The use of patient-reported information to influence care decisions has become an increasing focus 
of attention in primary care research and practice. ${ }^{49}$ The My Own Health Report (MOHR; www. myownhealthreport.org) project ${ }^{50}$ used interactive technology to assess health behaviors, mental health issues, quality of life, and patient preferences in the primary care setting. ${ }^{51,52}$ The goal of MOHR was to address a set of DIS questions: with what consistency could we collect patient-report measures (reach), and how well we could use them to set patient driven goals and provide feedback to patients, primary care providers, and staff across a wide variety of patient populations and clinical settings (implementation and effectiveness), and how successfully can this be done across diverse settings (adoption). The study used a cluster randomized, pragmatic trial design in 18 diverse primary care clinics across the country to assess the feasibility, costs, and impact of efforts to systematically collect and act on data related to patient-reported issues. The study team used the RE-AIM framework to design and evaluate the study. ${ }^{53}$

Key findings from MOHR indicated that it was feasible to collect and provide feedback on these patient-centered issues in diverse settings. Patients in MOHR clinics were more likely to set goals for improvement and reported greater changes in some behaviors. ${ }^{51}$ This was only possible by allowing local clinics to adapt and tailor the timing, modality, and language of the information gathering. Initial reports on the patterns and interrelationship of different health behaviors, time, and costs required and initial results have been published as referenced above.

\section{Example No. 2: Implementation of Care Management in Primary Care}

Care management is defined as the use of "systems, science, incentives, and information to improve medical practice and assist consumers and their support system to become engaged in a collaborative process designed to manage medical/social/ mental health conditions more effectively. The primary goal of care management is to achieve an optimal level of wellness and improve coordination of care while providing cost-effective, nonduplicative services. ${ }^{" 54}$ There has been a growing literature on the impact of care managers integrated in primary care practices. $^{55,56}$ Early results were promising; however, there were conflicting results on level of improvement in patient outcomes. ${ }^{57-61}$ The focus of our multiple care management studies was to answer the following DIS questions: What are the core components of care management, under what circumstances and in what settings does care management get adopted, implemented well, and maintained, what patient outcomes improve as a result of care management, and what are the most cost-effective implementation strategies for putting care management into place?

Using RE-AIM as a guide, we studied care management implementation by comparing different care management models within a natural experiment and by conducting a cluster-randomized controlled trial to examine the effects of practices having a care manager versus not having a care manager. These studies occurred in multiple physician organizations in Michigan. We found that implementation factors such as on-site care managers (ie, embedded in the practice team) and providing care management for all patients who needed it (instead of a small subset) were important implementation factors related to success. ${ }^{56,62,63}$ Care management where the care managers were off site and worked as an independent operation were not often utilized and therefore, fell short in delivering patient help and patient improvement outcomes. ${ }^{64,65}$

In both of these case studies, the use of RE-AIM helped uncover the factors important to making the adoption, implementation, and maintained use of evidence-based approaches successful.

\section{Key Issues and Future Directions}

As new innovations are being developed, they should be designed with an eye toward how they can eventually be used. This approach is often referred to as "designing for dissemination" and involves a set of processes that are considered and activities that are undertaken throughout the planning, development, implementation, and evaluation of an intervention to increase its dissemination and implementation potential. ${ }^{66}$ In fact, designing for dissemination is an emerging and important field within DIS. ${ }^{67}$

Another emerging topic within DIS is deimplementation. Deimplementation is the study of decreasing the use of interventions that have no utility, are wasteful, or for which harms outweigh benefits. A common area where this occurs in health care delivery is in the area of deprescribing, or deimplementation, particularly with regard to 
polypharmacy. An excellent primary care example is the Choosing Wisely program. Choosing Wisely (http://www.choosingwisely.org) is an initiative that seeks to advance a national dialog on avoiding wasteful or unnecessary medical tests, treatments, and procedures. Because many health care practices begin because of various cultural, political, or other reasons and reimbursement follows. Therefore, deimplementation has significant clinical implications and is often quite challenging.

How can primary care take advantage of DIS? There are numerous possibilities given that primary care medical practice is in a state of change. There are new interventions that can be incorporated into practice every day. Take the example of precision medicine. If medical treatments can be tailored based on patient's genetic profiles, how will that work? It will likely require new methods of counseling and referring patients and new workflows to accommodate the extra step in the treatment process. Questions arise including how consistently these procedures will be implemented, for which patients, and how much it costs the patient and the practice. These are all implementation issues. Assuming these are somewhat resolved, how does one disseminate these implementation methods to a diverse set of clinics in varying geographic areas with different contextual issues, resources, staffing, and patient populations?

\section{Where to Begin? Learning Steps and Resources}

A first step is to become familiar with theory and approaches for DIS. There are many excellent resources for this included in the Appendix. Another step is to reach out to the increasing cadre of colleagues who focus on DIS. They can be found attending the annual Academy Health/NIH DIS meeting, or are members of the Society for Implementation Research Collaborative (SIRC) or the VA Quality Enhancement Research Initiative (QUERI). A few journals are specifically focused on publishing DIS such as Implementation Science, Translational Behavioral Medicine, and BMC Health Services Research; however, other journals including the Fournal of the American Board of Family Medicine also publish DIS articles, including these recent examples. ${ }^{18,68-69}$

DIS is receiving increased attention not only in the United States, but equally or more so in Canada (where it is called Knowledge Translation), the United Kingdom, Europe, and elsewhere. Some of the most exciting emerging applications are in lowand middle-income countries, especially concerning task shifting and ways to use disruptive innovation strategies to dramatically increase reach and deliver interventions at a fraction of current cost. ${ }^{70-72}$ As the field is growing, there are increasing training opportunities for researchers seeking to become DIS scientists. In particular, the $\mathrm{Na}$ tional Cancer Institute sponsors a training program called the Training Institute for Dissemination and Implementation Research in Cancer (TIDIRC).

\section{Conclusion}

The field of DIS has tremendous potential for impact on the dissemination and implementation of evidence-based interventions and strategies in primary care. This new and evolving field of research will illuminate important factors that drive success. DIS is relevant and can provide fresh ideas, models, and evaluation approaches for primary care researchers, practices, practitioners, and patients. It can make a difference not only for patients, but also for those who work and conduct research in primary care.

To see this article online, please go to: http://jabfm.org/content/ 31/3/466.full.

\section{References}

1. Starfield B, Shi L, Macinko J. Contribution of primary care to health systems and health. Milbank Q 2005;83:457-502.

2. McNellis RJ, Genevro JL, Meyers DS. Lessons learned from the study of primary care transformation. Ann Fam Med 2013;11:S1-S5.

3. NCQA. Patient centered medical home recognition. Available from: http://www.ncqa.org/Programs/ Recognition/Practices/PatientCenteredMedicalHomePCMH.aspx. Accessed February 19, 2016.

4. Crabtree BF, Chase SM, Wise CG, et al. Evaluation of patient centered medical home practice transformation initiatives. Med Care. 2011;49: $10-6$.

5. Office of the National Coordinator. What is meaningful use? 2013. Available from: http://www. healthit.gov/providers-professionals/ehr-incentivescertification. Accessed December 11, 2013.

6. Estabrooks PA, Boyle M, Emmons KM, et al. Harmonized patient-reported data elements in the electronic health record: Supporting meaningful use by primary care action on health behaviors and key 
psychosocial factors. J Am Med Inform Assoc 2012; 19:575-82.

7. H.R.2. Medicare Access and CHIP Reauthorization Act of 2015. 2015. Available from: https://www. congress.gov/bill/114th-congress/house-bill/2. Accessed July 1, 2017.

8. Center for Medicare and Medicaid Services. The merit-based incentive program. November 29, 2106. Available from: https://www.cms.gov/Medicare/ Quality-Initiatives-Patient-Assessment-Instruments/ Value-Based-Programs/MACRA-MIPS-and-APMs/ Merit-based-Incentive-Payment-System-MIPSOverview-slides.pdf. Accessed July 1, 2017.

9. Puffer JC, Bazemore AW, Phillips RL, et al. Certification status of family physicians in the initial cohort entering maintenance of certification. J Am Board Fam Med 2014;27:581-2.

10. American Board of Fam Med Continuing certification. Available from: https://www.theabfm.org/ MOC/index.aspx. Accessed July 1, 2017.

11. Chambers DA, Feero WG, Khoury MJ. Convergence of implementation science, precision medicine, and the learning health care system: A new model for biomedical research. JAMA 2016;315: 1941-2.

12. Ward BW, Schiller JS, Goodman RA. Multiple chronic conditions among US adults: A 2012 update. Prev Chronic Dis 2014;11:E62.

13. Chetty UJ, O'Donnell P, Blane D, et al. The role of primary care in improving health equity: Report of a workshop held by the WONCA Health Equity Special Interest Group at the 2015 WONCA Europe Conference in Istanbul, Turkey. Int J Equity Health 2016;15:128.

14. Green LW, Ottoson JM, García C, Hiatt RA. Diffusion theory and knowledge dissemination, utilization, and integration in public health. Annu Rev Public Health 2009;30:151-74.

15. Colditz G. The promise and challenges of dissemination and implementation research. In: Brownson R, Colditz G, Proctor E, eds. Dissemination and implementation research in health: Translating science to practice. New York, NY: Oxford University Press; 2012; pp. 3-22.

16. Rabin BA, Brownson R. Developing the terminology for dissemination and implementation research. In: Brownson RC, Colditz G, Proctor E, eds. Dissemination and implementation research in health: Translating science to practice. 2nd ed. New York, NY: Oxford University Press; 2017; pp. 23-51.

17. Bauer MS, Damschroder L, Hagedorn H, et al. An introduction to implementation science for the nonspecialist. BMC Psychol 2015;3:32.

18. Heintzman J, Gold R, Krist A, et al. Practicebased research networks (PBRNs) are promising laboratories for conducting dissemination and implementation research. J Am Board Fam Med 2014;27:759-62.
19. Dolor R, Fagnan LJ. Dissemination and implementation research in primary care practice-based research networks. Ann Fam Med 2016;14:481-82.

20. Chambers DA, Glasgow RE, Stange KC. The dynamic sustainability framework: Addressing the paradox of sustainment amid ongoing change. Implement Sci 2013;8:117.

21. Chambers DA, Norton WE. The adaptome: Advancing the science of intervention adaptation. Am J Prev Med 2016;51:S124-S31.

22. Johnson JL, Green LW, Frankish CJ, et al. A dissemination research agenda to strengthen health promotion and disease prevention. Can J Public Health. 1996;87:S5-S10.

23. Rabin BA, Brownson R. Developing the terminology for dissemination and implementation research. In: Brownson R, Colditz G, Proctor E, eds. Dissemination and implementation research in health: Translating science to practice. New York, NY: Oxford University Press; 2012.

24. Kao L. Implementation science and quality improvement. In: Dimick JB Greenberg CC, eds. Success in academic surgery: Health services research. London, UK: Springer; 2014;85-100.

25. Batalden PB, Davidoff F. What is "quality improvement" and how can it transform healthcare? Qual Saf Health Care 2007;16:2-3.

26. Health Resources and Services Administration. Quality improvement. 2017. Available from: https:// www.hrsa.gov/quality/toolbox/methodology/ qualityimprovement/index.html. Accessed July 2, 2017.

27. Berwick DM. The science of improvement. JAMA 2008;299:1182-4.

28. Loudon K, Treweek S, Sullivan F, et al. The PRECIS-2 tool: Designing trials that are fit for purpose. BMJ 2015;350:h2147.

29. Department of Health and Human Services. Dissemination and implementation research in health (R01). 2017. Available fronm: https://grants.nih.gov/ grants/guide/pa-files/PAR-16-238.html. Accessed July 1, 2017.

30. Patient-Centered Outcomes Research Institute. Funding opportunities. 2017. Available from: http:// www.pcori.org/funding-opportunities. Accessed July 1, 2017.

31. Richesson RL, Hammond WE, Nahm M, et al. Electronic health records based phenotyping in nextgeneration clinical trials: A perspective from the NIH Health Care Systems Collaboratory. J Am Med Inform Assoc 2013;20:e226-e31.

32. Allen J, Linnan LA, Emmons KM. Fidelity and its relationship to implementation effectiveness, adaptation, and dissemination. In: Brownson R, Colditz G, Proctor E, eds. Dissemination and implementation research in health: Translating science to practice. New York, NY: Oxford University Press; 2012; 281-304. 
33. Holtrop JS, Rabin B, Glasgow RE. Qualitative approaches to use of the RE-AIM framework: Rationale and methods. BMC Health Serv Res 2018;18: 177.

34. Green CA, Duan N, Gibbons RD, et al. Approaches to mixed methods dissemination and implementation research: Methods, strengths, caveats, and opportunities. Adm Policy Ment Health 2015;42:508-23.

35. National Cancer Institute: Division of Cancer Control and Population Sciences. The QUALRIS Group Learning Community. 2017. Available from: https:// researchtoreality.cancer.gov/learning-communities/ qualris. Accessed July 1, 2017.

36. Tabak RG, Khoong EC, Chambers DA, Brownson RC. Bridging research and practice: Models for dissemination and implementation research. Am J Prev Med 2012;43:337-50.

37. Center for Research in Implementation Science and Prevention. Dissemination and implementation research models. Available from: http://www.dissemination-implementation.org. Accessed March 11, 2017.

38. Nilsen P. Making sense of implementation theories, models and frameworks. Implement Sci 2015;10:53.

39. Glasgow RE, Vogt TM, Boles SM. Evaluating the public health impact of health promotion interventions: The RE-AIM framework. Am J Public Health 1999;89:1322-7.

40. Gaglio B, Shoup JA, Glasgow RE. The RE-AIM framework: A systematic review of use over time. Am J Pub Health. 2013;103:e38-e46.

41. Shoup JA, Gaglio B, Varda D, et al. Network analysis of RE-AIM framework: Chronology of the field and the connectivity of its contributors. Transl Behav Med 2015;5:216-32.

42. Glasgow RE, Estabrooks PA. Pragmatic applications of RE-AIM for health care initiatives in community and clinical settings. Prev Chronic Dis. 2018;15:E02.

43. Feldstein A, Glasgow RE. A practical, robust implementation and sustainability model (PRISM) for integrating research findings into practice. Jt Comm J Qual Patient Saf 2008;34:228-43.

44. Liles EG, Schneider JL, Feldstein AC, et al. Implementation challenges and successes of a populationbased colorectal cancer screening program: A qualitative study of stakeholder perspectives. Implement Sci 2015;10:41.

45. Glasgow RE, Steiner JF. Comparative effectiveness research to accelerate translation: Recommendations for an emerging field of science. In: Brownson RC, Colditz GA, Proctor EK. eds. Dissemination and implementation research in health: Translating science into practice. New York, NY: Oxford University Press; 2012;82.

46. Moher D, Hopewell S, Schulz KF, et al. CONSORT 2010 Explanation and Elaboration: Up- dated guidelines for reporting parallel group randomised trials. J Clin Epidemiol 2010;63:e1-e37.

47. Glasgow R, Huebschmann A, Brownson R. Expanding the CONSORT to address representativeness and failure to replicate. 2017; In press.

48. Gaglio B, Glasgow R. Evaluation approaches for dissemination and implementation research. In: Brownson RC PE, Colditz G, ed. Dissemination and implementation research in health: Translating science to practice. New York, NY: Oxford University Press; 2017;317-34.

49. Alonso J, Bartlett SJ, Rose M, et al. The case for an international patient-reported outcomes measurement information system (PROMIS®) initiative. Health Qual Life Outcomes. 2013;11:210.

50. Krist AH, Glenn BA, Glasgow RE, et al. Designing a valid randomized pragmatic primary care implementation trial: the my own health report (MOHR) project. Implement Sci 2013;8:73.

51. Krist AH, Glasgow RE, Heurtin-Roberts S, et al. The impact of behavioral and mental health risk assessments on goal setting in primary care. Transl Behav Med 2016;6:212-9.

52. Krist AH, Phillips SM, Sabo RT, et al. Adoption, reach, implementation, and maintenance of a behavioral and mental health assessment in primary care. Ann Fam Med 2014;12:525-33.

53. Glasgow RE, Kessler RS, Ory MG, et al. Conducting rapid, relevant research: Lessons learned from the my own health report project. Am J Prev Med 2014;47:212-9.

54. Center for Health Care Strategies, Inc. Care management definition and framework. 2007. Available from: http://www.chcs.org/usr_doc/Care_Management_Framework.pdf. Accessed November 19, 2013.

55. Wiley JA, Rittenhouse DR, Shortell SM, et al. Managing chronic illness: Physician practices increased the use of care management and medical home processes. Health Aff (Millwood) 2015;34:78-86.

56. Taliani CA, Bricker PL, Adelman AM, et al. Implementing effective care management in the patientcentered medical home. Am J Manag Care 2013;19: 957-64.

57. Hong CS, Siegel AL, Ferris TG. Caring for highneed, high-cost patients: What makes for a successful care management program? Issue Brief (Commonw Fund) 2014;19:1-19.

58. Tomoaia-Cotisel A, Farrell TW, Solberg LI, et al. Implementation of care management: An analysis of recent AHRQ research. Med Care Res Rev 2018;75: 46-65.

59. Hsu J, Price M, Vogeli C, et al. Bending the spending curve by altering care delivery patterns: The role of care management within a pioneer ACO. Health Aff (Millwood) 2017;36:876-84.

60. Peikes D, Chen A, Schore J, Brown R. Effects of care coordination on hospitalization, quality of 
care, and health care expenditures among Medicare beneficiaries: 15 randomized trials. JAMA 2009;301:603-18.

61. Mattke S, Seid M, Ma S. Evidence for the effect of disease management: Is $\$ 1$ billion a year a good investment? Am J Manag Care 2007;13:670-6.

62. Daaleman TP, Hay S, Prentice A, et al. Embedding care management in the medical home: A case study. J Prim Care Community Health 2014;5:97-100.

63. Holtrop JS, Potworowski G, Fitzpatrick L, et al. Understanding effective care management implementation in primary care: A macrocognition perspective analysis. Implement Sci 2015;10:122.

64. Annis A, Holtrop JS, Tao M, et al. A comparison of health plan and provider-based targeting strategies for chronic disease care management. Am J Manag Care 2015;21:344-51.

65. Holtrop JS, Luo Z, Alexanders L. Inadequate reimbursement for care management to primary care offices. J Am Board Fam Med 2015;28:271-9.

66. Dearing JW, Kreuter MW. Designing for diffusion: How can we increase uptake of cancer communication innovations? Patient Educ Counsel 2010;8: S100-10.

67. Brownson RC, Jacobs JA, Tabak RG, et al. Designing for dissemination among public health researchers: Findings from a national survey in the United States. Am J Public Health 2013;103:1693-9.

68. Balasubramanian BA, Heurtin-Roberts S, Krasny S, et al. Factors related to implementation and reach of a pragmatic multisite trial: The My Own Health Report (MOHR) study. J Am Board Fam Med 2017; 30:337-49.

69. Kwan BM, Sills MR, Graham D, et al. Stakeholder engagement in a patient-reported outcomes (PRO) measure implementation: A report from the SAFTINet Practice-Based Research Network (PBRN). J Am Board Fam Med 2016;29:102-15.

70. World Health Organization. First global conference on task shifting. 2008. Available from: http:// www.who.int/healthsystems/task_shifting/en. Accessed July 1, 2017.

71. Munga MA, Kilima SP, Mutalemwa PP, et al. Experiences, opportunities and challenges of implementing task shifting in underserved remote settings: The case of Kongwa district, central Tanzania. BMC Int Health Hum Rights 2012;12:27.

72. O'Malley G, Asrat L, Sharma A, et al. Nurse task shifting for antiretroviral treatment services in $\mathrm{Na}$ mibia: Implementation research to move evidence into action. PLoS One 2014;9:e92014.

73. Glasgow RE, Fisher L, Strycker LA, et al. Minimal intervention needed for change: definition, use, and value for improving health and health research. Transl Behav Med. 2014;4:26-33.
Appendix: Dissemination and Implementation Science Key Resources

Key Books and Articles in Dissemination and

Implementation Science Research

Brownson, RC, Colditz, GA, Proctor, EK. Dissemination and implementation research in health: Translating science to practice. 2nd ed. New York, NY: Oxford University Press; 2018.

- Gold standard text on DIS research-Currently under revision with new edition expected in late 2017 or early 2018.

Chambers DA, Glasgow R, Stange, KC. The dynamic sustainability framework: Addressing the paradox of sustainment amid ongoing change. Implemen Sci 2013;8:117.

- The dynamic sustainability framework identifies key factors that may allow interventions to be sustainable and effective despite changing circumstances: 1) continued learning and problem solving, 2) ongoing adaptation of interventions with a primary focus on fit between interventions and multi-level contexts, and 3) expectations for ongoing improvement as opposed to diminishing outcomes over time.

Curran GM, Bauer M, Mittman B, et al. Effectiveness-implementation hybrid designs: Combining elements of clinical effectiveness and implementation research to enhance public health impact. Med Care 2012;50:217-26.

- This article proposes methods for blending design components of clinical effectiveness and implementation research. Such blending can provide benefits over pursuing these lines of research independently. For example, more rapid translational gains, more effective implementation strategies, and more useful information for decision makers.

Damschroeder L, Aron DC, Keith RE, Kirsh SR, Alexander JA, Lowery JC. Fostering implementation of health services research findings into practice: a consolidated framework for advancing implementation science. Implemen Sci 2009;4:50. 
- This is the seminal publication of the Consolidated Framework for Implementation Research (CFIR), see also cfirguide.org for more details and for guidance on use of the CFIR framework.

Feldstein AC, Glasgow RE. A practical, robust implementation and sustainability model (PRISM) for integrating research findings into practice. Jt. Comm J Qual Patient Saf 2008;34:228-243.

- This article describes the PRISM DIS framework-A comprehensive approach to implementation science. PRISM extends RE-AIM by incorporating concepts from Diffusions of Innovation theory and other models that emphasize the importance of context from the perspectives of intervention staff and participants, as well as the importance of building partnerships, and planning for program sustainability.

Gaglio B, Shoup JA, Glasgow RE. The RE-AIM framework: A systematic review of use over time. Am J Public Health. 2013;103(6):e38-e46.

- The RE-AIM framework continues to be widely used as an implementation science framework, and this article identifies how the use of RE-AIM has changed over time. See also the seminal REAIM publication: Glasgow RE, Vogt TM, Boles SM (1999). Evaluating the public health impact of health promotion interventions: the RE-AIM framework. Am J Public Health. 1999;89:13221327.

Glasgow RE, Riley T. Pragmatic measures: What they are and why we need them. Am J Prev Med 2013;45:237-43.

- This article proposes necessary and recommended criteria for pragmatic measures, provides examples of projects to develop and identify such measures, addresses potential concerns about these recommendations, and identifies areas for future research and application.

Glasgow RE, Chambers D, Khoury M, Kaplan R, Hunter C, Vinson C. National Institutes of Health to Dissemination and Implementation Science: Current status, future directions for integrating research, practice and policy. Am J Pub Health 2012; 102:1274-81.
- This article addresses the vast gap between current knowledge and practice in the area of dissemination and implementation research. Terminology, examples of successful applications of this research, key sources of support, and directions and opportunities for future advances are provided.

Grimshaw JM, Eccles MP, Lavis JN, Hill SJ, Squires JE. Knowledge translation of research findings. Implement Sci 2012;7:50.

- Summarizes the current concepts and evidence to guide knowledge translation activities and provides a Canadian (and European) perspective on the translation of new clinical knowledge into improved health. Addresses 5 key questions: what should be transferred; to whom should research knowledge be transferred; by whom should research knowledge be transferred; how should research knowledge be transferred; and, with what effect should research knowledge be transferred?

Kilbourne A, Elwy R, Sales A, Atkins D. Accelerating research impact in a learning health care system: VA's Quality Enhancement Research Initiative in the choice act era. Med Care 2017;55:S4S12.

- This article describes the Veterans Health Administration (VHA) Quality Enhancement Research Initiative (QUERI) that has supported more rapid implementation of research into clinical practice since 1998. Grounded in implementation science and evidence-based policy, QUERI serves as an example of how to operationalize core components of a Learning Health Care System, notably through rigorous evaluation and scientific testing of implementation strategies to ultimately reduce variation in quality and improve overall population health.

Loudon K, Treweek S, Sullivan F, et al. The PRECIS-2 tool: Designing trials that are fit for purpose. BMJ 2015;350:h2147.

- This article gives guidance on how to use an improved, validated version, PRECIS-2, which has been developed with the help of over 80 international trialists, clinicians, and policy makers. Keeping the original simple wheel format, 
PRECIS-2 now has 9 domains scored from 1 (very explanatory) to 5 (very pragmatic), to facilitate domain discussion and consensus.

Proctor EK, Silmere H, Raghavan R, et al Outcomes for implementation research: Conceptual distinctions, measurement challenges, and research agenda. Adm Policy Ment Health 2011;38:65-76.

- This article proposes a heuristic, working "taxonomy" of 8 conceptually distinct implementation outcomes-acceptability, adoption, appropriateness, feasibility, fidelity, implementation cost, penetration, and sustainability-along with their nominal definitions.

Proctor EK, Powell BJ, Baumann AA, Hamilton AM, Santens RL. Writing implementation research grant proposals: 10 key ingredients. Implement Sci 2012;7:96.

- This article describes key ingredients to getting a dissemination and implementation research proposal funded.

Pinnock, H, Barwick, L, Carpenter, CR, et al. Standards for Reporting Implementation Studies (StaRI) Statement. BMJ 2017;356:i6795.

- The StaRI criteria provide guidance for the outcomes that should be reported in D\&I research manuscripts.

\section{Recommended Web sites and On-line Resources}

National Cancer Institute Implementation Science Web site. General and NIH issues in D\&I: https:// cancercontrol.cancer.gov/is/staff.html.

In addition webinars, examples of successful D\&I grants, List of Research Tested Intervention Programs.
Selecting and adapting theories for DIS: www. Dissemination-Implementation.org.

Society for Implementation Research Collaboration (SIRC). National society that facilitates communications and collaborations among implementation science research teams, researchers, and community members:

https://societyforimplementationresearchcollaboration.org/.

University of Colorado Program in Dissemination and Implementation Science, including access to interactive tools and e-books:

http://www.ucdenver.edu/academics/colleges/ medicalschool/programs/ACCORDS/sharedresources/DandI/Pages/Dissemination \%20and\%20 Implementation.aspx.

Interactive e-learning books on DIS basics and terms:

http://www.crispebooks.org/PragmaticTrials/ Landing-1627 to $179 \mathrm{R} 3$.html.

http://www.crispebooks.org/PragmaticTrials/ workbook-1627 to 1845 R.html.

Resources and details on use of RE-AIM DIS framework: www.Reaim.org.

NIH funding for dissemination and implementation research (PAR 16-238): https://grants.nih. gov/grants/guide/pa-files/PAR-16 to 238.html.

Resources and details on use of the Consolidated Framework for Implementation Research framework: www.Cfirguide.org.

Resources on using the Pragmatic Explanatory Continuum Indicator Summary tool to assist research trialists to portray visually how pragmatic or explanatory their trial design is:

www.precis-2.org.

Washington University center for multiple resources and activities related to DIS, including trainings and talks: https://publichealth.wustl.edu/ centers/dissemination-implementation/. 